\title{
Uterine Fibroids: Burden and Unmet Medical Need
}

\author{
Ayman Al-Hendy, MD, PhD ${ }^{1} \quad$ Evan Robert Myers, MD $^{2} \quad$ Elizabeth Stewart, MD ${ }^{3}$
}

${ }^{1}$ Division of Translational Research, Department of Obstetrics and Gynecology, Augusta University, Augusta, Georgia

2 Division of Clinical and Epidemiological Research, Department of Obstetrics and Gynecology, Duke University Medical Center, Durham, North Carolina

${ }^{3}$ Department of Obstetrics and Gynecology and Surgery, Mayo Clinic, Rochester, Minnesota

Address for correspondence Ayman Al-Hendy, MD, PhD, Division of Translational Research, Department of Obstetrics and Gynecology, Augusta University, 1120 15th Street, Augusta, GA 30912 (e-mail: aalhendy@GRU.edu).

Semin Reprod Med 2017;35:473-480

\begin{abstract}
Keywords

- uterine fibroids

- disease burden

- economic burden

- unmet medical need

- leiomyomas

Uterine fibroids affect a wide cross-section of the population, with prevalence, symptom severity, and overall disease burden generally higher among black women, likely due to both genetic and environmental factors. Potential symptoms of uterine fibroids include painful and excessive uterine bleeding, interference with everyday life and self-image, and impaired fertility. Because of the high estimated prevalence and costs associated with treatments, the direct and indirect costs of uterine fibroids are substantial for both the health care system and the individual patient. Special patient populations-such as black women, women seeking to retain fertility, and women with asymptomatic fibroids-have particular treatment needs that require a variety of diagnostic methods and treatment options. Despite the widespread occurrence of uterine fibroids and newer treatment options, little high-quality data are available to formulate evidence-based guidelines that address these unmet patient needs. Specific areas in need of attention include improving diagnostic techniques, increasing patient access to early treatment, and identifying best practices for this diverse patient population.
\end{abstract}

Uterine fibroids (UFs) are a major public health concern, yet much is unknown about their underlying cause. Though prevalence of UF overall is high, treatment options are limited and may not be widely accessed by patients. To provide an overview of the UF disease state and context for the fibroid-focused articles following within this issue of Seminars in Reproductive Medicine, we summarize main findings for burden of disease, the widely varied experiences in special populations, and the current unmet needs in the UF patient population.

\section{Burden of Disease in the United States}

\section{Prevalence, Incidence, and Risk Factors}

Uterine fibroids are the most common benign pelvic tumors in women. Because many UFs are asymptomatic, estimating prevalence is difficult. ${ }^{1}$ In a recent systematic review, prevalence estimates range from 4.5 to $68.6 \%$, depending on study population and methodology, ${ }^{2}$ with prevalence increasing with age until menopause, then declining. ${ }^{1}$ This prevalence is higher than other conditions in women such as hypertension, ${ }^{3}$ breast cancer, ${ }^{4}$ or ovarian cancer. ${ }^{5}$ There are marked differences by race in both prevalence and incidence (-Fig. 1), with age-specific incidence and prevalence of UF higher in black women at all ages. ${ }^{1,2}$ Using ultrasound screening, the estimated cumulative incidence rate of UF by the age of 50 is significantly higher in black women (80\%) compared with white women (nearly $70 \%)^{6}$

The underlying pathogenesis of UF remains unclear. Several risk factors have been identified, ranging from genetic predisposition to variable lifestyle behaviors. A positive family history is a significant risk factor for developing UF; 7,8 however, the specific genetic component(s) of UF risk are not fully understood. New data suggest specific subgroups of genetic alterations; for example, genome-wide association studies and analyses of UF tumors have revealed several genetic and
Issue Theme Fibroids; Guest Editors, James H. Segars, $\mathrm{MD}$ and Ayman Al-Hendy, $\mathrm{MD}, \mathrm{PhD}$
DOI https://doi.org/

10.1055/s-0037-1607264. ISSN $1526-8004$.
Copyright @ 2017 by Thieme Medical Publishers, Inc., 333 Seventh Avenue, New York, NY 10001, USA. Tel: +1(212) 584-4662.
License terms

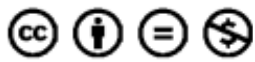



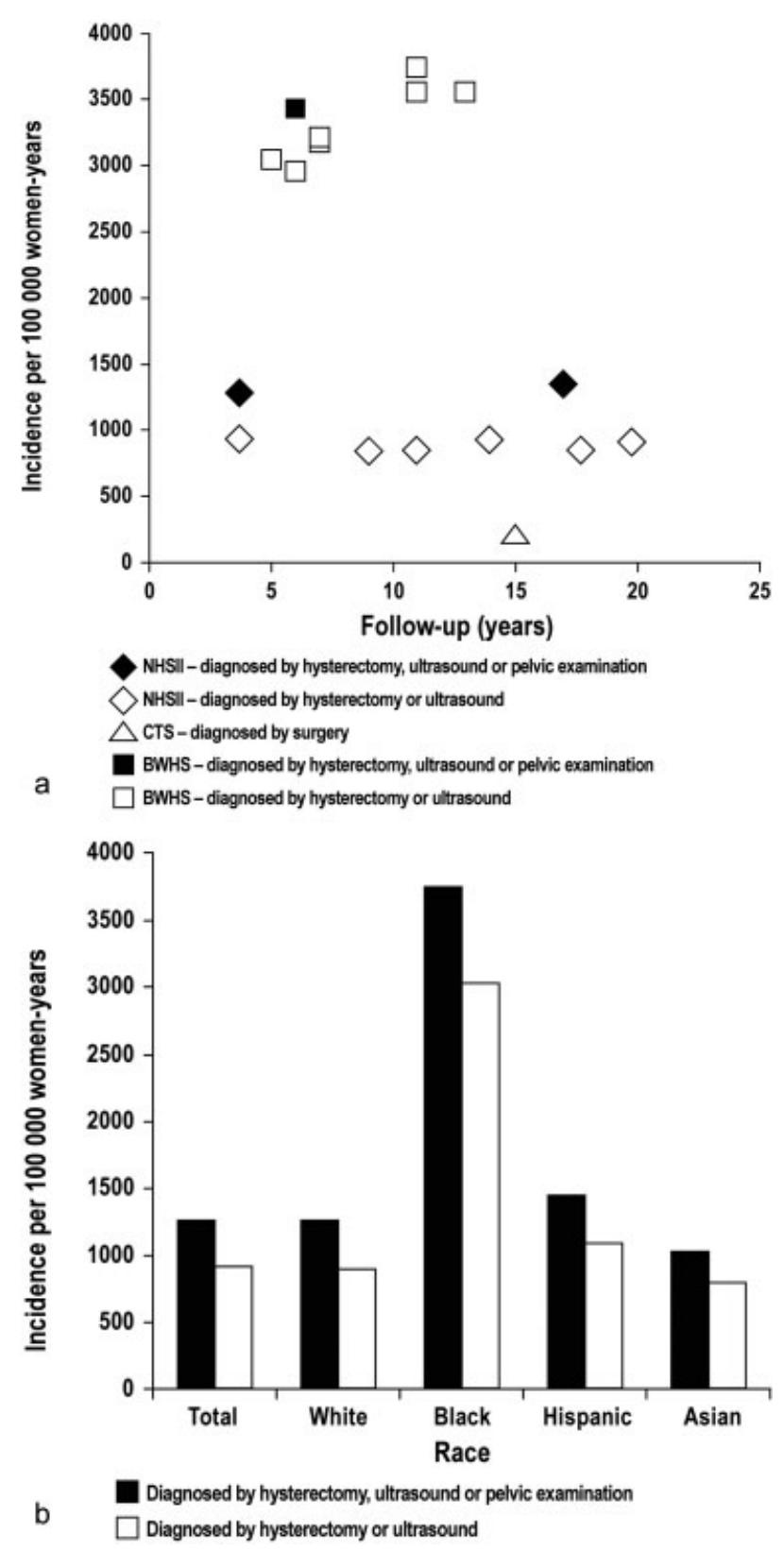

Fig. 1 Incidence of uterine fibroid in (a) registry studies from the United States and (b) according to race in the Nurses' Health Study. ${ }^{2}$ BWHS, Black Women's Health Study; CTS, California Teachers Study; NHSII, Nurses' Health Study II. (Image republished with permission of John Wiley and Sons, Inc., from Stewart et al; ${ }^{2}$ permission conveyed through Copyright Clearance Center, Inc.)

epigenetic factors that are correlated with an increased risk for UF. $^{9-18}$ Modifiable lifestyle factors that may significantly impact UF incidence include vitamin D deficiency, ${ }^{7,19-22}$ exercise and diet, ${ }^{23}$ smoking, ${ }^{24}$ obesity, ${ }^{7,23,25}$ contraceptive use, $^{23}$ and dyslipidemia. ${ }^{25-27}$ There is some evidence that vitamin D supplementation ${ }^{28}$ and statin use $^{29}$ have some protective effects. Together, these data suggest that several lifestyle factors may collectively contribute to the development of UF; further studies-including clinical trials of weight loss, exercise, and/or dietary modification for the prevention or treatment of symptomatic UF-are warranted.

\section{Symptoms and Impact of Symptomatic Disease}

Symptoms associated with UF can negatively impact daily living and quality of life (QoL). Symptoms vary by patient, but many women with UF have more than one symptom. Heavy menstrual bleeding (HMB), the most common symptom, occurs in about one-third of patients and can result in lifethreatening anemia. ${ }^{30}$ One retrospective study found that UF was the cause of bleeding in $48 \%$ of women discharged from the hospital having a diagnosis of HMB and extremely low hemoglobin levels. ${ }^{31}$ Along with HMB, UF-associated pain is another frequent problem reported by patients. ${ }^{32}$ The size and location of UF impacts pain during menstruation, but not during pre-menstruation or during sexual intercourse. ${ }^{32} \mathrm{How}-$ ever, fibroid size, often exceeding $10 \mathrm{~cm}$ in diameter, can lead to other "direct" or "bulk" symptoms such as abdominal protrusion; pelvic pressure; urinary urgency, frequency, or incontinence; and constipation and/or tenesmus. ${ }^{33,34}$

Not surprisingly, UFs are also associated with several adverse reproductive outcomes. They are associated with $10 \%$ of infertility cases and are the only identified cause of infertility in 1 to $3 \%$ of patients. ${ }^{35}$ UFs are also associated with several pregnancy-related complications, spontaneous abortion, preterm delivery, and cesarean delivery ${ }^{35}$-although the extent to which this association is causal rather than confounded by other factors associated with these outcomes, such as black race and older maternal age, is unclear.

The chronic nature of UF symptoms can ultimately have a severe impact on patients' day-to-day activities, making it challenging for patients to maintain emotional and psychological well-being. ${ }^{36-38}$ A common emotional response to UF is the concern of self-image and worth, which can contribute to difficulties in relationships. ${ }^{36,39}$ Fatigue and missing work due to UF are reported by many women. ${ }^{39,40}$ Indeed, UFs affect the health and effectiveness of women in a variety of workplace environments, including the military. ${ }^{41}$ Though women of many ethnic backgrounds report work-related symptoms, black women have a higher incidence and more often have severe or very severe work-related symptoms than white women. ${ }^{39,40}$

\section{Costs Affect Both Patients and the Health Care System} The annual cost of UF has been estimated to total 34.4 billion USD, which is more than breast cancer, colon cancer, or ovarian cancer, ${ }^{42}$ though less than cardiovascular disease. ${ }^{43}$

The indirect costs of UF due to loss of work-estimated to be 1.6 to 17.2 billion USD annually-were identified as the most expensive annual UF-related cost. ${ }^{42}$ However, the direct costs are also substantial. UFs are the most common cause of hysterectomy in the United States, contributing to approximately 30 to $50 \%$ of all hysterectomies. ${ }^{44,45}$ Additionally, hysterectomy is the most common surgery for UF management, accounting for approximately $75 \%$ of UF-related surgeries. $^{45,46}$ Like other inpatient and outpatient surgical treatments, hysterectomy, myomectomy, uterine artery embolization (UAE), and endometrial ablation ${ }^{34}$ lead to significant direct costs for fibroid-related surgeries, hospital admissions, outpatient visits, and prescriptions. ${ }^{47-49}$ The annual direct cost of UF was recently estimated to be 4.1 to 9.4 billion USD 
Table 1 Estimated costs per patient and overall costs of patients with UF in the United States

\begin{tabular}{|c|c|c|c|c|c|}
\hline \multirow[b]{2}{*}{ Reference } & \multicolumn{4}{|c|}{ Per patient calculation, USD } & \multirow{2}{*}{$\begin{array}{l}\text { Total costs, billions USD } \\
\text { Cardozo et } \text { al }^{42, m}\end{array}$} \\
\hline & Soliman et $\mathrm{al}^{47}$ & Borah et $\mathrm{al}^{48}$ & Cain-Nielsen et al $^{49}$ & Cardozo et al ${ }^{42}$ & \\
\hline Direct & $9,319-9,473^{a}$ & na & na & na & $4.1-9.4$ \\
\hline $\begin{array}{l}\text { Direct with } \\
\text { surgery }\end{array}$ & $15,878-21,603^{b}$ & $19,763-25,019^{9}$ & $15,249-18,653^{h}$ & na & na \\
\hline $\begin{array}{l}\text { Medical } \\
\text { management }\end{array}$ & $3,704^{c}$ & na & na & $5,563-8,665^{j}$ & $3.2-5.1$ \\
\hline Surgical & $6,201-16,049^{d}$ & na & na & $4,943-14,850^{k}$ & $0.83-4.3$ \\
\hline Inpatient & $3,923-8,218$ & na & na & na & na \\
\hline Outpatient & $1,243-4,643^{e}$ & na & na & na & na \\
\hline Indirect & $2,399-15,549^{e}$ & na & na & na & na \\
\hline $\begin{array}{l}\text { Loss of work } \\
\text { productivity }\end{array}$ & $2,685-33,172^{f}$ & na & na & $4,449-30,075$ & $1.6-17.2$ \\
\hline $\begin{array}{l}\text { Obstetric } \\
\text { complications }\end{array}$ & na & na & na & $2,335-57,458^{1}$ & $0.24-7.8$ \\
\hline Total & $11,717-25,023^{\mathrm{e}}$ & na & $21,232-22,819^{i}$ & na & $5.9-34.4$ \\
\hline
\end{tabular}

Abbreviations: na, not available; UF, uterine fibroid; USD, U.S. dollars.

aRange of averages reported across all patients regardless of treatment, per patient per year.

${ }^{\mathrm{b}}$ Cost totaled for 1 year postsurgery, among patients who underwent surgery.

'Utah Medicaid database for patients on medical management only, from diagnosis to procedure or menopause.

${ }^{\mathrm{d}}$ Cost per patient per hospitalization.

${ }^{\mathrm{e}}$ Per patient in the year following diagnosis.

fLower estimate is costs due to work loss from diagnosis to menopause compared with a healthy woman; upper range is estimated as loss of productivity in 1 year following hysterectomy.

${ }^{9}$ One-year all-cause costs for women who received magnetic resonance image-guided focused ultrasound (MRgFUS), myomectomy, and uterine artery embolization (UAE).

${ }^{\mathrm{h}}$ Mean costs for myomectomy, MRgFUS, and UAE.

'Mean costs for myomectomy, MRgFUS, and UAE, as well as productivity costs.

'Includes medications, inpatient admission, and outpatient visits.

kEstimates from hysterectomy, myomectomy, UAE, endometrial ablation.

'Ranges estimated from spontaneous abortions, cesarean delivery, and preterm delivery costs.

${ }^{m}$ Calculated by multiplying the number of women aged 25 to 64 in the United States in $2010(63,930,821)$ by the percent of women who sought treatment for symptomatic fibroid tumors annually $(0.92 \%)$ by published per-patient cost ranges.

(- Table 1). ${ }^{42,47-49}$ Obstetric-related complications alone contributed 4 to $23 \%$ of the total annual cost. ${ }^{42}$ With complications and recurrence common, costs for treatment can last for at least 10 years. ${ }^{50}$ Indeed, patients with UF incurred significantly higher health care resource utilization and costs than those without UF, both pre- and postdiagnosis, with UF patients having medical costs of an average of $\$ 1,435$ higher in the total 5 -year prediagnosis and $\$ 11,188$ higher in the total 5-year postdiagnosis. ${ }^{50}$ These data support the need for research that aims to compare the effectiveness and relative costs of available treatment options for UF.

\section{Special Populations}

\section{Black Women}

The burden of disease attributable to UF is substantially higher for black women than for other racial or ethnic groups. The incidence of UF in the United States is up to three times greater among black women compared with white women. ${ }^{6,51}$ Black women develop UF at a younger age, on average around 5.3 years younger than white women. ${ }^{52}$
Black women also have larger and greater numbers of UFs than white women and are more likely to report severe disease than white women of similar socioeconomic status. ${ }^{40,52,53}$ This in turn contributes to a higher risk of complications with surgical treatment. ${ }^{54}$

Furthermore, analyses from women $\geq 45$ years of age demonstrated that tumors from older white women grew much more slowly than those from older black women (2 vs. $15 \%$ growth rate), and the UF in white women, but not those in black women, demonstrated a significant decline in growth rate with age. ${ }^{55}$

Regardless of race, having a family history of UF is a risk factor, ${ }^{7,8}$ suggesting that UF susceptibility has a genetic basis. However, no genome-wide association study has recruited enough black women to determine whether genomic loci exist for UF specifically in black women that could explain the increased incidence and symptom severity in this group. In contrast, studies testing for genomic loci associated with increased incidence of other diseases, such as prostate cancer and nondiabetic end-stage renal disease, have been performed in black populations, with several candidate loci 
identified. ${ }^{56}$ Interestingly, certain lifestyle factors may contribute to this higher incidence of UF among black women in the United States, as this group is known to consume smaller amounts of dairy, fruits, vegetables, and vitamins; ${ }^{23,57}$ have a higher prevalence of obesity; ${ }^{23}$ and have higher rates of vitamin D deficiency. ${ }^{58}$ A negative correlation also was observed between serum vitamin D levels and total UF volume, which was significant for black women but not for white women. ${ }^{22}$ Hair relaxers, used by millions of black women, have also been linked to an increased risk of UF. ${ }^{59}$

The disparity of UF incidence and severity among races can lead to differences in treatment outcomes. For example, women of African origin living in Europe have more severe symptoms of UF, with surgical interventions at younger ages. ${ }^{34}$ For women who experience symptoms at a younger age and have more severe disease, surgical treatments may have a bigger impact on reproductive outcomes, including age at menopause. ${ }^{60,61}$ Black women may also experience higher rates of recurrence than white women following surgical treatment; recurrence can be as high as 59\% within 5 years. ${ }^{34}$ Race may also affect response to pharmacologic treatment. ${ }^{62}$ Despite having higher disease burden, black women may have more difficulty accessing appropriate care and in some cases may have a flawed understanding of the disease. $^{63,64}$

\section{Women with Infertility Pursuing Treatment Options}

For patients who seek treatment, the decision must incorporate fertility wishes. Many women experiencing infertility or recurrent miscarriage are found to have UF, though these may be unrelated to reproductive dysfunction. ${ }^{65}$ A complete fertility or recurrent miscarriage evaluation should be conducted on both partners before addressing UF as a putative cause. Though procedural removal of UF can be performed in women who wish to retain fertility, there remains uncertainty about the impact of procedural treatment, ${ }^{66}$ and outcomes on fertility may depend on the location of the UF. Subserosal UFs-which project to the outside of the uterus-appear to not affect fertility. ${ }^{65}$ Submucosal UFswhich project into the uterine cavity-are most important because data suggest that removal can improve fertility outcomes. $^{67}$ Finally, intramural UFs-which grow within the muscular uterine wall-decrease fertility, though removal of intramural UF does not seem to improve fertility and data remain controversial. ${ }^{68,69}$

Procedural treatments range from surgical (e.g., hysterectomy, myomectomy) to "minimally invasive," such as UAE and magnetic resonance image-guided focused ultrasound (MRgFUS). Though a small randomized study found that fertility was less improved with UAE compared with myomectomy, ${ }^{70}$ additional research is needed to support this low-level evidence. ${ }^{71}$ MRgFUS is a less invasive procedural treatment option for women with UF; one preliminary study of pregnancies in 51 women who previously underwent MRgFUS treatment for UF reported a $41 \%$ rate of successful (live birth) pregnancies. ${ }^{72}$ Myomectomy of submucosal UF has been reported capable of increasing fertility rates in nonrandomized trials, ${ }^{66}$ but based on a systematic review there is insufficient evidence to evaluate the role of myomectomy on fertility improvement. ${ }^{68}$ More research is needed to determine the benefit of surgical intervention on other classes of UF. Despite the potential for increasing fertility, none of these treatments result in long-term efficacy, as additional interventions are equally common following UAE, MRgFUS, and myomectomy. ${ }^{73}$ There are several major challenges to determining the effect of procedural treatments on reproductive outcomes. First, many women being treated for UF who are interested in future fertility are "older" in terms of fecundity (meaning both fewer overall pregnancies and a longer time to pregnancy), and at risk for pregnancy complications, including miscarriage. The combination of low numbers of pregnancies and higher risk for complications results in relatively small numbers of measurable outcomes; so, studies with very large numbers of participants are needed for meaningful analysis. $^{74}$

Pharmacologic treatment in women with UF who desire to retain fertility can also be complicated. Though oral contraceptives and intrauterine devices (IUDs) can decrease bleeding, there is a limited understanding of their efficacy in treating UF; further, they do not have FDA approval to treat UF; so, their use remains controversial. ${ }^{75,76}$ Gonadotropinreleasing hormone agonists ( $\mathrm{GnRHa}$ ) are approved by the FDA for short-term, preoperative use. However, UFs regrow rapidly following cessation of treatment. ${ }^{30}$ Aromatase inhibitors also are used; yet, uncertainty remains about their effectiveness. $^{74}$ Several selective progesterone receptor modulators (SPRMs) have been developed ${ }^{77}$ that have demonstrated an ability to rapidly reduce menstrual bleeding and fibroid volume, with minimal effects on estrogen levels. ${ }^{78}$ Ulipristal acetate (UPA) is a SPRM approved in Europe and Canada for preoperative treatment of moderate-to severe symptoms of UF in women of reproductive age, and also in Europe for intermittent treatment of moderateto-severe symptoms of UF. ${ }^{78}$ SPRMs offer potential for longer-term medical treatment, potentially allowing patients to avoid surgical intervention and/or preserve fertility. ${ }^{77,78}$ One important consideration about any pharmacologic treatment is that any treatment targeting estrogen or progesterone action is likely to either have a contraceptive effect or to be contraindicated for use during pregnancy. This is likely to be true as well for any treatments targeting abnormal collagen deposition in UF. This means medical treatments will likely need to be stopped for some period of time prior to attempting pregnancy, with a potential risk of recurrence of UF.

\section{Women with Asymptomatic Uterine Fibroids}

About 50 to $75 \%$ of UF cases remain asymptomatic. ${ }^{45}$ Small or asymptomatic UF can be identified-often incidentallyupon pelvic imaging. ${ }^{30}$ It remains unclear if earlier treatment would reduce risk of developing symptoms, adverse reproductive outcomes, and/or the need for future invasive procedures. ${ }^{45}$ Because it is established that UF can regress as well as grow, ${ }^{55}$ understanding how to trigger the regression program would be an innovative treatment option. Research of women with asymptomatic UF is warranted to more completely understand the natural history of UF and 
determine if treatment can prevent progression to symptomatic disease.

\section{Unmet Needs}

\section{Improved Diagnostic Techniques}

There is a lack of consensus on what and how to report imaging findings with the currently available diagnostic tools. For example, the Federation of Gynecology and Obstetrics (FIGO) subclassification system for $\mathrm{UF}^{79}$ is not routinely reported in imaging reports; yet, FIGO subclassification is an important factor influencing safety and efficacy of some treatment options. ${ }^{45}$ Women with UF may also have additional reproductive pathologies-such as ovulatory disorders, adenomyosis, and endometriosis-that require consideration before treatment is initiated. ${ }^{45}$ Additionally, as reported by the FDA in a special communication, approximately 1 in every 350 women undergoing hysterectomy or myomectomy for UF was found to also have uterine sarcoma, ${ }^{80}$ though recent estimates are lower, especially for younger premenopausal women. ${ }^{81,82}$ The lack of a reliable method to ascertain whether a woman diagnosed with UF may have uterine sarcoma can result in mistreatment, as some types of surgical intervention for UF may spread cancer within the abdomen and pelvis, worsening prognosis. ${ }^{80}$ Research using diffusion-weighted and contrast-enhanced magnetic resonance imaging to address this issue is ongoing. ${ }^{83,84}$

\section{More Effective, Fertility-Preserving, Well-Tolerated Treatments}

Current UF treatments do not optimize future fertility and are associated with additional medical complications and/or recurrence. Beyond the direct and indirect costs associated with reintervention after recurrence, repeated myomectomies significantly increase risk of complications beyond UF, such as pelvic adhesions. ${ }^{34,85}$ With so few available therapies, it is not surprising that a recent systematic network meta-analysis stated that regardless of a woman's plans for future surgery, there is "insufficient evidence to recommend any medical treatment in the management of UF." ${ }^{86}$ To optimize treatments, research focused on comparative effectiveness is essential.

\section{Enhanced Patient Education/Empowerment}

The limited treatment options can reduce treatment-seeking behavior. For many women, lack of awareness regarding UF and normal menstruation may lead to living with the condition chronically without seeking care. ${ }^{87}$ One recent study estimated that women waited an average of 3.6 years before seeking treatment for UF-related symptoms. ${ }^{39}$

It remains unclear why some women with UF-related symptoms do not seek treatment. In a recent survey of women with UF, half expressed feelings of helplessness and believed that they had no control over their UF, and several women felt a lack of substantial support for their related emotional issues. ${ }^{36}$ While the study was limited to a certain geographical area, it is possible that many women believe that treatment will not be effective, or they simply have limited access to care.

\section{Expanded Access to Treatment}

For patients who desire procedural treatment, access can be difficult for those in rural areas due to the requirement for specialized skills or equipment for performance. ${ }^{88,89}$ In addition, treatment can be cost-prohibitive, due to substantial direct and indirect costs. ${ }^{42,47}$ Some treatment options are deemed experimental by insurers following approval by the FDA because of lack of data from large randomized trials. ${ }^{90}$

\section{Identification of Best Practices}

The tremendously diverse patient population imposes challenges for health care providers' ability to implement a "best practice" approach to UF treatment. Though guidelines for the management and treatment of UF have been published by various organizations-including ACOG (American Congress of Obstetricians and Gynecologists), SOGC (Society of Obstetricians and Gynecologists of Canada), and AAGL (American Association of Gynecologic Laparoscopists) ${ }^{91-93}$ -treatment guidelines may be limited by a paucity of recommendations based on good and consistent scientific evidence. Thus, identification and implementation of best practices for effective management and treatment of UF are greatly needed. ${ }^{74}$ Further development of treatment guidelines that incorporate high-quality evidence from clinical trials may avoid overtreatment with hysterectomy by using a multidisciplinary approach including regular UF evaluations. This may facilitate the increased use of less invasive options over hysterectomy for symptomatic UF.

\section{Conclusion}

Uterine fibroids affect a large segment of the population and can negatively impact daily living and QoL of those affected, resulting in severe occupational and economic costs. Black women in particular have a substantially higher disease burden. UF, as well as treatments for it, can cause either temporary or permanent infertility. Thus, surgical and pharmacologic treatments that preserve or regain fertility are being pursued, though with limited success. Techniques to improve diagnosis and associated diseases, to improve fertility-preserving treatments, and to increase patient access and action are the current unmet needs in this population.

\section{Acknowledgments}

The authors acknowledge the editorial and writing contributions of Bryn Gaertner, PhD, and Sarah Prins, PhD, of Prescott Medical Communications Group, Chicago, IL.

\section{References}

1 Drayer SM, Catherino WH. Prevalence, morbidity, and current medical management of uterine leiomyomas. Int J Gynaecol Obstet 2015;131(02):117-122

2 Stewart EA, Cookson CL, Gandolfo RA, Schulze-Rath R. Epidemiology of uterine fibroids: a systematic review. BJOG 2017;124(10):1501-1512

3 Roger VL, Go AS, Lloyd-Jones DM, et al; American Heart Association Statistics Committee and Stroke Statistics Subcommittee. Heart disease and stroke statistics-2012 update: a report from the American Heart Association. Circulation 2012;125(01):e2-e220 
4 Breastcancer.org. Breast Cancer Statistics. Available at: http://www. breastcancer.org/symptoms/understand_bc/statistics. Accessed September 26, 2017

5 NCI. SEER Cancer Stat Facts: Ovarian Cancer. National Cancer Institute Web Site. http://seer.cancer.gov/statfacts/html/ovary. html. Accessed September 26, 2017

6 Baird DD, Dunson DB, Hill MC, Cousins D, Schectman JM. High cumulative incidence of uterine leiomyoma in black and white women: ultrasound evidence. Am J Obstet Gynecol 2003;188(01): 100-107

7 Ciebiera M, Włodarczyk M, Słabuszewska-Jóźwiak A, Nowicka G, Jakiel $G$. Influence of vitamin $D$ and transforming growth factor $\beta 3$ serum concentrations, obesity, and family history on the risk for uterine fibroids. Fertil Steril 2016;106(07):1787-1792

8 Van Voorhis BJ, Romitti PA, Jones MP. Family history as a risk factor for development of uterine leiomyomas. Results of a pilot study. J Reprod Med 2002;47(08):663-669

9 Navarro A, Yin P, Monsivais D, et al. Genome-wide DNA methylation indicates silencing of tumor suppressor genes in uterine leiomyoma. PLoS One 2012;7(03):e33284

10 Maekawa R, Sato S, Yamagata Y, et al. Genome-wide DNA methylation analysis reveals a potential mechanism for the pathogenesis and development of uterine leiomyomas. PLoS One 2013;8(06):e66632

11 Mehine M, Kaasinen E, Mäkinen N, et al. Characterization of uterine leiomyomas by whole-genome sequencing. $\mathrm{N}$ Engl J Med 2013;369(01):43-53

12 Eggert SL, Huyck KL, Somasundaram P, et al. Genome-wide linkage and association analyses implicate FASN in predisposition to uterine leiomyomata. Am J Hum Genet 2012;91(04):621-628

13 Cha PC, Takahashi A, Hosono N, et al. A genome-wide association study identifies three loci associated with susceptibility to uterine fibroids. Nat Genet 2011;43(05):447-450

14 Gallagher CS, Morton CC. Genetic association studies in uterine fibroids: risk alleles presage the path to personalized therapies. Semin Reprod Med 2016;34(04):235-241

15 Yatsenko SA, Mittal P, Wood-Trageser MA, et al. Highly heterogeneous genomic landscape of uterine leiomyomas by whole exome sequencing and genome-wide arrays. Fertil Steril 2017; 107(02):457-466.e9

16 Yang Q, Mas A, Diamond MP, Al-Hendy A. The mechanism and function of epigenetics in uterine leiomyoma development. Reprod Sci 2016;23(02):163-175

17 Mäkinen N, Heinonen HR, Moore S, Tomlinson IP, van der Spuy ZM, Aaltonen LA. MED12 exon 2 mutations are common in uterine leiomyomas from South African patients. Oncotarget 2011;2(12): 966-969

18 Mehine M, Mäkinen N, Heinonen HR, Aaltonen LA, Vahteristo P. Genomics of uterine leiomyomas: insights from high-throughput sequencing. Fertil Steril 2014;102(03):621-629

19 Brakta S, Diamond JS, Al-Hendy A, Diamond MP, Halder SK. Role of vitamin D in uterine fibroid biology. Fertil Steril 2015;104(03): 698-706

20 Mitro SD, Zota AR. Vitamin D and uterine leiomyoma among a sample of US women: findings from NHANES, 2001-2006. Reprod Toxicol 2015;57:81-86

21 Paffoni A, Somigliana E, Vigano' P, et al. Vitamin D status in women with uterine leiomyomas. J Clin Endocrinol Metab 2013;98(08): E1374-E1378

22 Sabry M, Halder SK, Allah AS, Roshdy E, Rajaratnam V, Al-Hendy A. Serum vitamin D3 level inversely correlates with uterine fibroid volume in different ethnic groups: a cross-sectional observational study. Int J Womens Health 2013;5:93-100

23 Sparic R, Mirkovic L, Malvasi A, Tinelli A. Epidemiology of uterine myomas: a review. Int J Fertil Steril 2016;9(04):424-435

24 Wong JY, Chang PY, Gold EB, Johnson WO, Lee JS. Environmental tobacco smoke and risk of late-diagnosis incident fibroids in the Study of Women's Health across the Nation (SWAN). Fertil Steril 2016;106(05):1157-1164
25 Tak YJ, Lee SY, Park SK, et al. Association between uterine leiomyoma and metabolic syndrome in parous premenopausal women: a casecontrol study. Medicine (Baltimore) 2016;95(46):e5325

26 Korkmaz V, Ozkaya E, Özer Kadife S, Kara F, Kucukozkan T. Investigation of cardiovascular disease risk in women with uterine leiomyomas. Ir J Med Sci 2016;185(03):689-693

27 Uimari O, Auvinen J, Jokelainen J, et al. Uterine fibroids and cardiovascular risk. Hum Reprod 2016;31(12):2689-2703

28 Ciavattini A, Delli Carpini G, Serri M, et al. Hypovitaminosis D and "small burden" uterine fibroids: opportunity for a vitamin D supplementation. Medicine (Baltimore) 2016;95(52):e5698

29 Borahay MA, Fang X, Baillargeon JG, Kilic GS, Boehning DF, Kuo YF. Statin use and uterine fibroid risk in hyperlipidemia patients: a nested case-control study. Am J Obstet Gynecol 2016;215(06): 750.e1-750.e8

30 Bartels CB, Cayton KC, Chuong FS, et al. An evidence-based approach to the medical management of fibroids: a systematic review. Clin Obstet Gynecol 2016;59(01):30-52

31 Nelson AL, Ritchie JJ. Severe anemia from heavy menstrual bleeding requires heightened attention. Am J Obstet Gynecol 2015;213(01):97.e1-97.e6

32 David M, Pitz CM, Mihaylova A, Siedentopf F. Myoma-associated pain frequency and intensity: a retrospective evaluation of 1548 myoma patients. Eur J Obstet Gynecol Reprod Biol 2016;199:137-140

33 Gupta S, Jose J, Manyonda I. Clinical presentation of fibroids. Best Pract Res Clin Obstet Gynaecol 2008;22(04):615-626

34 Donnez J, Dolmans MM. Uterine fibroid management: from the present to the future. Hum Reprod Update 2016;22(06):665-686

35 Levy G, Hill MJ, Beall S, Zarek SM, Segars JH, Catherino WH. Leiomyoma: genetics, assisted reproduction, pregnancy and therapeutic advances. J Assist Reprod Genet 2012;29(08):703-712

36 Ghant MS, Sengoba KS, Recht H, Cameron KA, Lawson AK, Marsh EE. Beyond the physical: a qualitative assessment of the burden of symptomatic uterine fibroids on women's emotional and psychosocial health. J Psychosom Res 2015;78(05):499-503

37 Zimmermann A, Bernuit D, Gerlinger C, Schaefers M, Geppert K. Prevalence, symptoms and management of uterine fibroids: an international internet-based survey of 21,746 women. BMC Womens Health 2012;12:6

38 Downes E, Sikirica V, Gilabert-Estelles J, et al. The burden of uterine fibroids in five European countries. Eur J Obstet Gynecol Reprod Biol 2010;152(01):96-102

39 Borah BJ, Nicholson WK, Bradley L, Stewart EA. The impact of uterine leiomyomas: a national survey of affected women. Am J Obstet Gynecol 2013;209(04):319.e1-319.e20

40 Stewart EA, Nicholson WK, Bradley L, Borah BJ. The burden of uterine fibroids for African-American women: results of a national survey. J Womens Health (Larchmt) 2013;22(10):807-816

41 Armed Forces Health Surveillance Center (AFHSC). Uterine fibroids, active component females, U.S. Armed Forces, 20012010. MSMR 2011;18(12):10-13

42 Cardozo ER, Clark AD, Banks NK, Henne MB, Stegmann BJ, Segars $\mathrm{JH}$. The estimated annual cost of uterine leiomyomata in the United States. Am J Obstet Gynecol 2012;206(03):211.e1-211.e9

43 Go AS, Mozaffarian D, Roger VL, et al; American Heart Association Statistics Committee and Stroke Statistics Subcommittee. Executive summary: heart disease and stroke statistics-2013 update: a report from the American Heart Association. Circulation 2013; 127(01):143-152

44 Merrill RM. Hysterectomy surveillance in the United States, 1997 through 2005. Med Sci Monit 2008;14(01):CR24-CR31

45 Stewart EA, Laughlin-Tommaso SK, Catherino WH, Lalitkumar S, Gupta D, Vollenhoven B. Uterine fibroids. Nat Rev Dis Primers 2016;2:16043

46 Borah BJ, Laughlin-Tommaso SK, Myers ER, Yao X, Stewart EA. Association between patient characteristics and treatment procedure among patients with uterine leiomyomas. Obstet Gynecol 2016;127(01):67-77 
47 Soliman AM, Yang H, Du EX, Kelkar SS, Winkel C. The direct and indirect costs of uterine fibroid tumors: a systematic review of the literature between 2000 and 2013. Am J Obstet Gynecol 2015;213 (02):141-160

48 Borah BJ, Carls GS, Moore BJ, Gibson TB, Moriarty JP, Stewart EA. Cost comparison between uterine-sparing fibroid treatments one year following treatment. J Ther Ultrasound 2014;2(10):7

49 Cain-Nielsen AH, Moriarty JP, Stewart EA, Borah BJ. Cost-effectiveness of uterine-preserving procedures for the treatment of uterine fibroid symptoms in the USA. J Comp Eff Res 2014;3(05): 503-514

50 Fuldeore M, Yang H, Soliman AM, Winkel C. Healthcare utilization and costs among women diagnosed with uterine fibroids: a longitudinal evaluation for 5 years pre- and post-diagnosis. Curr Med Res Opin 2015;31(09):1719-1731

51 Marshall LM, Spiegelman D, Barbieri RL, et al. Variation in the incidence of uterine leiomyoma among premenopausal women by age and race. Obstet Gynecol 1997;90(06):967-973

52 Huyck KL, Panhuysen CI, Cuenco KT, et al. The impact of race as a risk factor for symptom severity and age at diagnosis of uterine leiomyomata among affected sisters. Am J Obstet Gynecol 2008; 198(02):168.e1-168.e9

53 Kjerulff KH, Langenberg P, Seidman JD, Stolley PD, Guzinski GM. Uterine leiomyomas. Racial differences in severity, symptoms and age at diagnosis. J Reprod Med 1996;41(07):483-490

54 Roth TM, Gustilo-Ashby T, Barber MD, Myers ER. Effects of race and clinical factors on short-term outcomes of abdominal myomectomy. Obstet Gynecol 2003;101(5, Pt 1):881-884

55 Peddada SD, Laughlin SK, Miner K, et al. Growth of uterine leiomyomata among premenopausal black and white women. Proc Natl Acad Sci U S A 2008;105(50):19887-19892

56 Wise LA, Ruiz-Narvaez EA, Palmer JR, et al. African ancestry and genetic risk for uterine leiomyomata. Am J Epidemiol 2012;176 (12):1159-1168

57 Wise LA, Radin RG, Palmer JR, Kumanyika SK, Rosenberg L. A prospective study of dairy intake and risk of uterine leiomyomata. Am J Epidemiol 2010;171(02):221-232

58 Baird DD, Hill MC, Schectman JM, Hollis BW. Vitamin D and the risk of uterine fibroids. Epidemiology 2013;24(03):447-453

59 Wise LA, Palmer JR, Reich D, Cozier YC, Rosenberg L. Hair relaxer use and risk of uterine leiomyomata in African-American women. Am J Epidemiol 2012;175(05):432-440

60 Moorman PG, Myers ER, Schildkraut JM, Iversen ES, Wang F, Warren N. Effect of hysterectomy with ovarian preservation on ovarian function. Obstet Gynecol 2011;118(06):1271-1279

61 Trabuco EC, Moorman PG, Algeciras-Schimnich A, Weaver AL, Cliby WA. Association of ovary-sparing hysterectomy with ovarian reserve. Obstet Gynecol 2016;127(05):819-827

62 Murji A, Crosier R, Chow T, Ye XY, Shirreff L. Role of ethnicity in treating uterine fibroids with ulipristal acetate. Fertil Steril 2016; 106(05):1165-1169

63 Ekpo GE, Ghant MS, Woodley LM, Recht HS, McKnight T, Marsh EE. Knowledge of uterine fibroid symptoms and presentation among African-American women: a pilot study. J Reprod Med 2014;59 (9-10):448-454

64 Sengoba KS, Ghant MS, Okeigwe I, Mendoza G, Marsh EE. Racial/ Ethnic differences in women's experiences with symptomatic uterine fibroids: a qualitative assessment. J Racial Ethn Health Disparities 2017;4(02):178-183

65 Ezzati M, Norian JM, Segars JH. Management of uterine fibroids in the patient pursuing assisted reproductive technologies. Womens Health (Lond) 2009;5(04):413-421

66 Olive DL. The surgical treatment of fibroids for infertility. Semin Reprod Med 2011;29(02):113-123

67 Purohit P, Vigneswaran K. Fibroids and infertility. Curr Obstet Gynecol Rep 2016;5:81-88

68 Metwally M, Cheong YC, Horne AW. Surgical treatment of fibroids for subfertility. Cochrane Database Syst Rev 2012;11:CD003857
69 Pritts EA, Parker WH, Olive DL. Fibroids and infertility: an updated systematic review of the evidence. Fertil Steril 2009;91(04): 1215-1223

70 Mara M, Maskova J, Fucikova Z, Kuzel D, Belsan T, Sosna O. Midterm clinical and first reproductive results of a randomized controlled trial comparing uterine fibroid embolization and myomectomy. Cardiovasc Intervent Radiol 2008;31(01):73-85

71 Gupta JK, Sinha A, Lumsden MA, Hickey M. Uterine artery embolization for symptomatic uterine fibroids. Cochrane Database Syst Rev 2014;(12):CD005073

72 Rabinovici J, David M, Fukunishi H, Morita Y, Gostout BS, Stewart EA; MRgFUS Study Group. Pregnancy outcome after magnetic resonance-guided focused ultrasound surgery (MRgFUS) for conservative treatment of uterine fibroids. Fertil Steril 2010;93(01):199-209

73 Gorny KR, Borah BJ, Brown DL, Woodrum DA, Stewart EA, Hesley GK. Incidence of additional treatments in women treated with MR-guided focused US for symptomatic uterine fibroids: review of 138 patients with an average follow-up of 2.8 years. J Vasc Interv Radiol 2014;25(10):1506-1512

74 Gliklich RE, Leavy MB, Velentgas P, et al. Identification of future research needs in the comparative management of uterine fibroid disease: a report on the priority-setting process, preliminary data analysis, and research plan. Effective Healthcare Research Report No. 31. Agency for Healthcare Research and Quality. https://www.effectivehealthcare.ahrq.gov/ehc/products/152/642/DEcIDE31_UterineFibroid_03-07-2011.pdf. Published March. Accessed January 9, 2017

75 Jacoby VL, Jacoby A, Learman LA, et al. Use of medical, surgical and complementary treatments among women with fibroids. Eur J Obstet Gynecol Reprod Biol 2014;182:220-225

76 Zapata LB, Whiteman MK, Tepper NK, Jamieson DJ, Marchbanks PA, Curtis KM. Intrauterine device use among women with uterine fibroids: a systematic review. Contraception 2010;82(01):41-55

77 Wagenfeld A, Saunders PT, Whitaker L, Critchley HO. Selective progesterone receptor modulators (SPRMs): progesterone receptor action, mode of action on the endometrium and treatment options in gynecological therapies. Expert Opin Ther Targets 2016;20(09):1045-1054

78 Taylor DK, Holthouser K, Segars JH, Leppert PC. Recent scientific advances in leiomyoma (uterine fibroids) research facilitates better understanding and management. F1000 Res 2015;4 (F1000 Faculty Rev):183

79 Munro MG, Critchley HO, Broder MS, Fraser IS; FIGO Working Group on Menstrual Disorders. FIGO classification system (PALM-COEIN) for causes of abnormal uterine bleeding in nongravid women of reproductive age. Int J Gynaecol Obstet 2011;113(01):3-13

80 Cancer.org. Available at: https://www.cancer.org/latest-news/fdawarns-of-cancer-risk-in-a-type-of-uterine-fibroid-surgery.html. Accessed September 26, 2017

81 Pritts EA, Vanness DJ, Berek JS, et al. The prevalence of occult leiomyosarcoma at surgery for presumed uterine fibroids: a meta-analysis. Gynecol Surg 2015;12(03):165-177

82 Mao J, Pfeifer S, Zheng XE, Schlegel P, Sedrakyan A. Populationbased estimates of the prevalence of uterine sarcoma among patients with leiomyomata undergoing surgical treatment. JAMA Surg 2015;150(04):368-370

83 Li HM, Liu J, Qiang JW, Zhang H, Zhang GF, Ma F. Diffusion-weighted imaging for differentiating uterine leiomyosarcoma from degenerated leiomyoma. J Comput Assist Tomogr 2017;41(04):599-606

84 Sumi A, Terasaki H, Sanada S, et al. Assessment of MR imaging as a tool to differentiate between the major histological types of uterine sarcomas. Magn Reson Med Sci 2015;14(04):295-304

85 Donnez J, Donnez O, Dolmans MM. With the advent of selective progesterone receptor modulators, what is the place of myoma surgery in current practice? Fertil Steril 2014;102(03):640-648

86 Gurusamy KS, Vaughan J, Fraser IS, Best LM, Richards T. Medical therapies for uterine fibroids - a systematic review and network meta-analysis of randomised controlled trials. PLoS One 2016; 11(02):e0149631 
480 Uterine Fibroids: Burden and Unmet Medical Need Al-Hendy et al.

87 Ghant MS, Sengoba KS, Vogelzang R, Lawson AK, Marsh EE. An altered perception of normal: understanding causes for treatment delay in women with symptomatic uterine fibroids. J Womens Health (Larchmt) 2016;25(08):846-852

88 Patel PR, Lee J, Rodriguez AM, et al. Disparities in use of laparoscopic hysterectomies: a nationwide analysis. J Minim Invasive Gynecol 2014;21(02):223-227

89 Radley DC, Schoen C. Geographic variation in access to care-the relationship with quality. N Engl J Med 2012;367(01):3-6

90 Experimental technology poses pricey dilemma for hospitals. Available at: http://www.modernhealthcare.com/article/20140510/MAGAZINE/305109979. Accessed September 26, 2017
91 American College of Obstetricians and Gynecologists. ACOG practice bulletin. Alternatives to hysterectomy in the management of leiomyomas. Obstet Gynecol 2008;112 (02, Pt 1):387-400

92 Vilos GA, Allaire C, Laberge PY, Leyland N; SPECIAL CONTRIBUTORS. The management of uterine leiomyomas. J Obstet Gynaecol Can 2015;37(02):157-178

93 American Association of Gynecologic Laparoscopists (AAGL): Advancing Minimally Invasive Gynecology Worldwide. AAGL practice report: practice guidelines for the diagnosis and management of submucous leiomyomas. J Minim Invasive Gynecol 2012; 19(02):152-171 